\title{
A METODOLOGIA BSCEQ NA SELEÇÃO DE MATERIAIS PARA OTIMIZAÇÃO DO DESGASTE DE COROAS DE PERFURAÇÃO DE UMA INDÚSTRIA DE SONDAGEM
}

Zirlene Alves da Silva Santos ' Claudiano de Jesus de Souza ${ }^{2}$ Adilson Rodrigues da Costa ${ }^{3}$

\section{Resumo}

Atualmente, as empresas buscam aumentar o desempenho dos componentes e equipamentos, sendo o desgaste um fator que influencia nesse comportamento. Objetiva-se, neste estudo, demonstrar a aplicabilidade da metodologia Balanced Scorecard da Engenharia da Qualidade, para otimização do desgaste das coroas de perfuração, com base no caso de uma empresa de sondagem mineral, contemplando pesquisa bibliográfica, pesquisa de campo, brainstorming, análise por microscopia óptica, análise estatística e ensaios de desgaste de materiais amostrados das coroas de perfuração. Para isso, analisou-se o desgaste por abrasão em função da composição química das coroas consideradas adequadas à sondagem geológica. Em seguida, realizou-se análise estatística com a técnica DOE (fatorial $2^{\mathrm{K}}$ ). A combinação dos materiais resultou no protótipo que foi submetido a ensaio de desgaste com esfera rotativa utilizando abrasivo representativo da litologia. É possível concluir que o planejamento realizado com base na metodologia BSCEQ aprimora a seleção de materiais.

Palavras-chave: Desgaste; Seleção de materiais; Experimentos; Balanced scorecard.

\section{METHOLOGY BSCEQ IN THE SELECTION OF MATERIALS OPTIMIZATION OF WEAR CROWNS OF A DRILLING INDUSTRY}

\begin{abstract}
Nowadays companies look for increasing the performance of components and equipments. One influential factor of that performance is their wear. Therefore, the aim of this study is to demonstrate the suitability of Balanced Scorecard from Quality Engineering (BSCQE) to optimize the wear of the crowns used for rock drilling. The methodology consists on bibliography search, field research, brainstorming, optical microscopy, statistic analysis and wear tests simulating abrasion conditions. The statistic analysis with which perform ball abrasive wear tests particularly using the DOE (factorial $2^{k}$ ) allows to built a prototype. It is concluded that the planning done based on the methodology BSCEQ improved materials selection.
\end{abstract}

Key words: Materials selection; Wear components; Experiments; Balanced scorecard.

\section{INTRODUÇÃO}

No Brasil, a discussão acadêmica e empresarial sobre o tema desgaste de materiais de engenharia é recente. Há menos de vinte anos, começou a ser considerado como gerador de perdas de produtividade e aumento de custo. Enquanto o país era afetado pela inflação alta, considerava-se a depreciação na visão contábil, sem que se analisassem os ônus reais. Como um equipamento pode ter a vida útil abreviada em função do desgaste precoce de componentes, pode haver maior custo de manutenção, perdas em produção, em energia, na qualidade de produtos e serviços e causar fadiga humana. Nesse sentido, torna-se necessário analisar como é desenvolvida a seleção dos materiais que compõem o produto ou o revestem, em relação à aplicação, para que haja aumento de vida útil de componentes, ferramentais e equipamentos.

\footnotetext{
'Graduada em Administração e Doutora em Engenharia de Materiais, Rede Temática de Materiais, Universidade Federal de Ouro Preto - UFOP, Cep 35400-000, Ouro Preto, MG, Brasil.E-mail: santoszirlene@em.ufop.br

${ }^{2}$ Graduado em Física e Mestre em Engenharia de Materiais, Rede Temática de Materiais, Universidade Federal de Ouro Preto - UFOP, Cep 35400-000, Ouro Preto, MG, Brasil. E-mail: claudiano.j@gmail.com

${ }^{3}$ Graduado em Engenharia Metalúrgica, Doutor em Ciências, Rede Temática de Materiais, Universidade Federal de Ouro Preto - UFOP,

Cep 35400-000, Ouro Preto, MG, Brasil.E-mail: adilson@em.ufop.br
} 
A sondagem mineral, área deste estudo, é a prospecção do solo por meio de equipamentos que fazem a extração de amostras e um dos principais componentes utilizados é a coroa, produzida com a combinação de pós-metálicos, como W, Fe, $\mathrm{Cu}, \mathrm{Co}$. Portanto, na sondagem mineral as perfuratrizes possuem coroas que são introduzidas no solo. Ferreira ${ }^{(1)}$ verifica a necessidade de se adotarem metodologias que permitam produzir coroas apropriadas às condições litológicas brasileiras, com base na análise do desempenho das coroas comerciais em operação na sondagem geológica praticada atualmente.

Objetiva-se, neste estudo, analisar a contribuição da metodologia BSCEQ para a seleção dos materiais, utilizando a ferramenta DOE (Design of Experiment) Planejamento de Experimentos - para a elaboração do produto coroas por meio de uma combinação adequada dos materiais.

\section{DESENVOLVIMENTO}

\section{I Desgaste}

Caracteriza-se como desgaste a perda de material da superfície de um corpo como consequência da interação com outro corpo. As condições para que haja desgaste exigem, ainda, movimento relativo entre as superfícies em contato e um abrasivo.(2) $O$ desgaste de componentes é um grande desafio para as empresas do setor minerometalúrgico, no qual a maior incidência é de desgaste abrasivo. Para Hutchings ${ }^{(2)}$ apud Nunes, ${ }^{(3)}$ define-se desgaste como a deterioração de uma superfície sólida que envolve perda progressiva de material, promovida em consequência do movimento relativo entre as superfícies somado à ação de partículas abrasivas duras ou, às vezes, de protuberâncias forçadas contra a superfície. Segundo Zum-Gahr, ${ }^{(4)}$ o desgaste abrasivo é definido como deslocamento de material causado por partículas duras presentes entre duas superfícies em movimento relativo. Essas partículas podem se encontrar soltas na superfície ou incrustadas em uma delas, gerando o desgaste. No processo de sondagem, a coroa é um componente da perfuratriz, fixada normalmente na ponta da haste que faz o avanço. Sua composição é variada. Normalmente, são fabricadas várias peças contendo materiais rígidos, como tungstênio ou diamante, dispersos em matriz metálica.

O grande desafio é desenvolver uma peça que atenda à litologia, pois o solo pode ser fraturável, friável e compacto. O solo fraturável é caracterizado por fragmentos com diferentes diâmetros. O solo friável é identificado por ser fino e solto, enquanto o solo compacto tem característica rochosa. As empresas, para adequar o desgaste das coroas às várias litologias, têm de investigar materiais que, combinados, equilibrem a perda. Trata-se de usar uma combinação que garanta desgaste adequado às condições litológicas. Por exemplo, no caso de solos compactos, recomenda-se que a matriz possua dureza inferior à que seria utilizada em solos fraturáveis. Para auxiliar na investigação e no processo de seleção dos materiais, é recomendável utilizar a combinação de propriedades, estrutura, processo, forma e desempenho.

Para Pintaúde, ${ }^{(5)}$ a seleção de materiais resistentes ao desgaste abrasivo resume-se em maximizar a dureza sem prejuízo da tenacidade à fratura. $\mathrm{O}$ autor afirma que as propostas de Kruschov e Richardson levaram pesquisadores, como Zum-Gahr, ${ }^{(4)}$ a definir como abrasivo "duro" aquele que possui dureza $20 \%$ maior que a dureza da superfície desgastada ou dureza $50 \%$ maior que a dureza inicial que antecede o processo de desgaste. De acordo com Gates, ${ }^{(7)}$ falta referência o desgaste abrasivo deve ser classificado com o objetivo de agrupar situações práticas que tenham características comuns e que possam ser tratadas de maneira similar.

Os aspectos característicos podem ser divididos em três grupos:

- Situação - descrição das condições macroscópicas que produzem o desgaste, como geometria do contato e das partículas abrasivas, tensões e velocidade de deslizamento;

- Mecanismos - processos microscópicos pelos quais os fragmentos de desgaste são gerados; e

- Manifestações - fenômenos observáveis, como taxas de desgaste, transições de taxas de desgaste e características da superfície desgastada e dos fragmentos gerados.

Grande parte das pesquisas relativas ao desgaste é desenvolvida por ensaios laboratoriais utilizando dentre outros equipamentos, aquele em que uma esfera gira apoiada sobre a superfície de interesse.

Para todos os pesquisadores na área de tribologia, o desgaste abrasivo de um material com coeficiente de desgaste $(K)$ pode ser calculado usando-se a equação de Archard (Equação I). Trata-se de uma equação que representa o fenômeno abrasivo geral, que se apresenta na forma:

$$
Q=K \frac{W}{H}
$$

onde:

- Q é a quantidade de material "removido" em $\mathrm{mm}^{3} /$ unidade de deslizamento;

- W é a força normal em newton $(\mathrm{N})$ aplicada à superfície de menor dureza;

- H é a dureza Vickers da superfície mais macia; e

- Ké o coeficiente de desgaste (adimensional).

É importante destacar que, em aplicações de engenharia, a razão $\frac{K}{H}$ é muito utilizada. O símbolo $K$ é chamado de coeficiente de desgaste específico, e indica o volume do material removido pela distância de desli- 
zamento (m) e a carga no contato, a normal (N). Para cálculo do volume teórico de perda de material no ensaio com esfera rotativa utiliza-se, dentre outras, a Equação 2 proposta por Hutchings:

$$
V(R, b)=\frac{\pi b^{4}}{64 R}
$$

onde:

- R é o raio da esfera; e

- b é o raio da calota.

Para Cruz, ${ }^{(6)}$ a Equação 3, desenvolvida por Cassino et al., é pertinente para ensaios em amostras relativos a cálculo do volume de material removido:

$$
V(R, r)=\frac{2}{3} \pi R^{3}-\frac{2}{3} \pi R^{2} \cdot \sqrt{R^{2}-r^{2}}-\frac{1}{3} \pi r^{2} \cdot \sqrt{R^{2}-r^{2}}
$$

onde:

- $R$ e $r$ são os raios da esfera e da projeção da calota, respectivamente; e

- V é o volume teórico da calota impressa na matriz.

A Equação 3 permite calcular o volume teórico da calota impressa no material. De posse desse dado é possível acompanhar a evolução temporal do desgaste realizando ensaios com duração distinta.

\subsection{Seleção de Materiais por Meio da Metodologia Balanced Scorecard de Engenharia da Qualidade-BSCEQ}

Da demanda pela otimização do desgaste das coroas de perfuração mineral, surge a necessidade de selecionar os materiais adequados ao projeto das coroas. Neste trabalho, opta por utilizar a metodologia a BSCEQ, uma ferramenta de gestão utilizada, desde a década de 1990, para medir o desempenho sob as perspectivas de processos internos, aprendizado e crescimento, visão financeira e clientes. Essa ferramenta contribui para ampliar a visão da empresa como forma de assegurar as tomadas de decisão, estabelecer metas e métodos que garantam a melhoria do desempenho dos negócios. $O$ modelo foi criado por David Norton e pelo consultor acadêmico Robert Kaplan, ambos da Universidade de Harvard. Para Kaplan e Norton, ${ }^{(8)}$ há necessidade de mudança nos sistemas de gestão e medição de desempenho, já que, feitas somente com indicadores financeiros, prejudicam a capacidade das organizações de criar valor econômico para o futuro. Os estudos realizados e apresentados demonstraram que a metodologia BSCEQ, para que seja eficaz na seleção de materiais, demanda uma técnica experimental de apoio. No caso das coroas de perfuração, a técnica de Planejamento de Experimentos agrega valor à metodologia, por permitir análise estatística da melhor combinação entre os materiais para produção das coroas. Por intermédio do Planejamento de Experi- mentos podem-se estabelecer configurações otimizadas de materiais por meio da análise das melhores combinações entre variáveis controláveis e resultados desejados. Trata-se de uma técnica amplamente utilizada na Engenharia da Qualidade. Para Juran, ${ }^{(9)} \circ$ Planejamento de Experimentos é um processo criativo baseado, em grande parte, na perícia tecnológica ou funcional. Montgomery ${ }^{(10)}$ apresenta os benefícios advindos da utilização do DOE:

- Redução do número de ensaios sem prejuízo da qualidade da informação;

- Estudo simultâneo de diversas variáveis, separando seus efeitos;

- Determinação da confiabilidade dos resultados;

- Realização da pesquisa em etapas, num processo iterativo de acréscimo de novos ensaios;

- Seleção das variáveis que influem num processo com número reduzido de ensaios;

- Representação do processo estudado através de expressões matemáticas; e

- Elaboração de conclusões a partir de resultados qualitativos.

Para o sucesso e a confiabilidade de um experimento, além da aplicação das técnicas experimentais e ferramentas estatísticas, é necessário que sejam observadas algumas etapas importantes de avaliação. Para Montgomery, ${ }^{(10)}$ tem de haver reconhecimento e relato do problema, pois o experimento deve ter o máximo de informações sobre o problema a ser analisado. Um relato claro do problema e dos objetivos do experimento contribuem substancialmente para a compreensão do processo e para a solução, ou seja, a saída. Assim, o BSCEQ analisa perspectivas dos processos internos, clientes internos e externos, visão financeira, aprendizado e crescimento do sistema produtivo, para que as variáveis controláveis possam ser selecionadas, conforme ilustra a Figura 2.

O BSCEQ, como ilustrado na Figura I, apresenta as entradas, que são a perspectiva da empresa e a perspectiva de clientes externos ou internos, que revelam a necessidade de mudança ou melhoria, do ponto de vista estratégico. A perspectiva de processos internos parte de dados oriundos do campo, que estão relacionados ao desempenho das coroas e materiais, para confecção das coroas, utilizados durante o processo de sondagem no qual, em termos tribológicos, prevalece a abrasão. As variáveis ou fatores controláveis contemplados para o planejamento de experimentos são definidos inicialmente por esses dados. Após a definição do desempenho esperado, são analisados os materiais utilizados para confecção da peça ou matriz. A perspectiva financeira destaca a relação custo $\times$ benefício. Já a perspectiva de aprendizado e crescimento mostra que método, máquina, mão de obra, matéria prima, medida e meio ambiente são variáveis ou fatores não controláveis, que podem influenciar no desempenho do componente. O desempenho das variáveis não controláveis gera instabilidade no sistema produtivo e pode interferir no desgaste de componentes. 


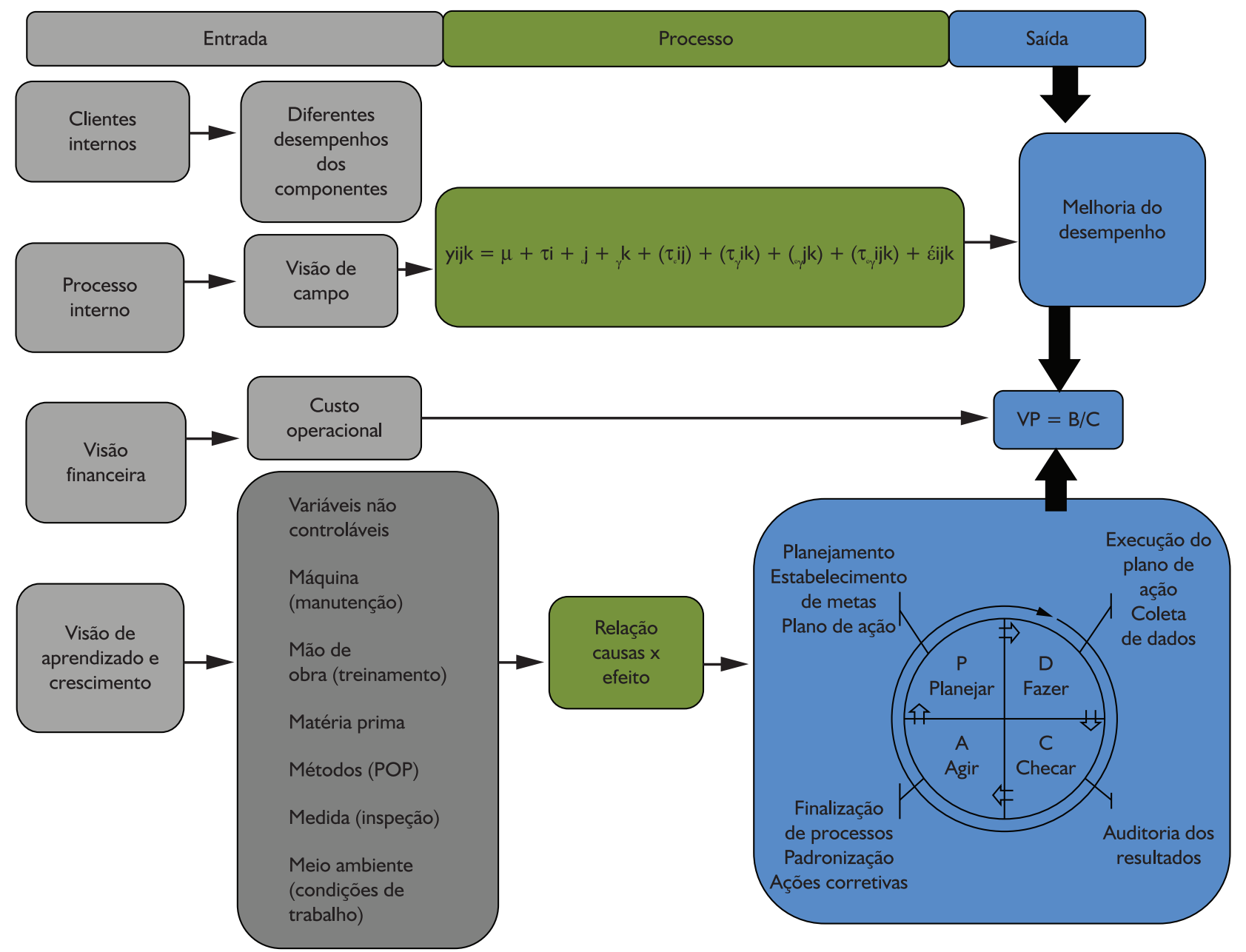

Figura I. Fluxograma da Metodologia BSCEQ.

O processo ilustrado no fluxograma da metodologia sugere a utilização do experimento $2^{k}$,definido por uma equação capaz de gerar várias combinações dos fatores controláveis envolvidos no experimento com o resultado de desempenho esperado pela empresa. Ainda na seleção dos materiais, utiliza-se a relação causa $\times$ efeito para identificar, analisar e bloquear as causas de variabilidade. O elemento saída é caracterizado por dois resultados: a combinação dos materiais que gera o produto final (conforme expectativa da empresa) e a adoção do modelo gerencial PDCA para melhoria contínua. Para aplicar a metodologia BSCEQ no processo de sondagem, na busca do melhor desempenho das coroas, é necessário indicar os materiais e métodos que foram facilitadores para alcançar os objetivos.

\section{MATERIAL E MÉTODOS}

Os materiais e métodos utilizados seguiram um fluxo com dados coletados por meio de visitas em campo e ensaios laboratoriais. Em campo foi utilizado o Brainstor- ming - um ambiente de discussões, troca de informações e ideias. A visita de campo possibilitou conhecer os equipamentos de perfuração, desenvolvimento das coroas utilizadas e a litologia. No laboratório, foram realizados ensaios de desgaste em pesquisa de mestrado utilizando equipamento composto por uma célula de carga, platô - onde a amostra é fixada; esfera de aço que gera atrito com a amostra e onde é gotejada a suspensão; e a massa suspensa. Foram ensaiadas 10 amostras de coroas na fábrica identificadas por números, que possuíam diferentes composições químicas representativas das coroas utilizadas em campo. As amostras foram pesadas para registro de sua massa inicial $\left(M_{i}\right)$. Foi utilizada suspensão de sílica com concentração de $0,25 \mathrm{~g} / \mathrm{mL}$, com granulometria média $19,52 \mu \mathrm{m}$, que, segundo pesquisa de campo, era similar às condições litológicas. Logo depois, as coroas foram submetidas ao ensaio de desgaste utilizando tempo (t) 60 minutos e gotejamento de abrasivo, com periodicidade de I minuto. Após os ensaios, as amostras de coroas foram analisadas por microscopia óptica utilizando microscópio LEIKA 4500, para medição das projeções 
calotas impressas. Os resultados da microscopia foram analisados com o propósito de comparar a perda de material, com base no diâmetro das projeções das calotas. Com as informações foram definidas as perspectivas dos clientes internos. Os dados dos ensaios de desgaste e da fábrica possibilitaram identificar as variáveis do processo. A perspectiva financeira foi delineada pelos gestores e a perspectiva de aprendizado e crescimento refere-se à relação causa e efeito no que tange a manutenção de máquinas; padrões operacionais; treinamento de mão de obra; variação da matéria prima; medidas de desempenho utilizadas, entre outros. A Tabela I apresenta os padrões definidos para realização dos ensaios de desgaste, aos quais o protótipo foi submetido.

Os resultados laboratoriais foram apresentados aos técnicos de campo e comparados com o desempenho das coroas no processo. Segundo eles, as coroas de melhor desempenho em campo eram as identificadas pelas numerações 3, 5, 7 e 10, cujas amostras já haviam sido submetidas aos ensaios. A pesquisa de campo revelou a demanda de um tipo de coroa com desgaste otimizado, ou seja, que não necessitasse de várias trocas durante uma única sondagem e reduzisse assim o custo operacional e o tempo gasto nas trocas. Considerando a pesquisa de

Tabela I. Parâmetros do ensaio de desgaste dos protótipos

\begin{tabular}{lc}
\hline Massa inicial & $22,80 \mathrm{~g}$ \\
Suspensão $\mathrm{SiO}_{2}-\mathrm{pH} 5,4 \mathrm{I}$ & $0,25 \mathrm{~g} / \mathrm{mL}$ \\
Granulometria média da sílica & $19,52 \mu \mathrm{m}$ \\
Diâmetro da esfera de aço & $17,5 \mathrm{~mm}$ \\
Inclinação do platô & $30^{\circ}$ \\
Carga & $240 \mathrm{~g}$ \\
Tempo & $60^{\prime}$ \\
\hline
\end{tabular}

campo, os diâmetros das calotas impressas nas amostras foram utilizados como variável controlável para o planejamento de experimento, assim como a composição química dessas. A composição possui: $\mathrm{Fe}, \mathrm{Co}, \mathrm{Cu}$, carboneto de silício e carboneto de tungstênio. Como variável controlável foi também contemplado o tamanho de grão do carboneto de tungstênio - entre $5 \mu \mathrm{m}-7 \mu \mathrm{m}$.

\section{RESULTADOS E DISCUSSÃO}

Após aplicação da metodologia, é possível demonstrar que, na visão dos clientes internos, produzia-se grande número de coroas com especificações e desempenhos diferentes, impactando o custo operacional. Não era possível definir uma única coroa que atendesse à litologia, sendo necessário utilizar várias, o que tornava mais onerosa a operação. $\mathrm{Na}$ perspectiva do processo interno, que retrata o campo, foram colocados muitos questionamentos sobre o desempenho das coroas e classificadas as coroas de números $3,5,7$ e 10 como sendo as de melhor desempenho. A terceira perspectiva reflete o impacto financeiro que ficou definido como custo operacional e, dessa forma, estava correlacionado com as outras duas perspectivas. A quarta perspectiva refere-se às habilidades e competências da organização para lidar com o efeito (desgaste), ou seja, relação existente entre método, mão de obra, matéria prima, máquinas, meio ambiente e medida com o efeito existente. A aplicação da metodologia revelou a melhor combinação dos materiais utilizados na confecção das coroas 3, 5, 7 e 10, conforme representado nas Figuras 2 e 3 . A Figura 2 ilustra os efeitos padronizados, enquanto a Figura 3 apresenta a probabilidade normal existente entre as variáveis.

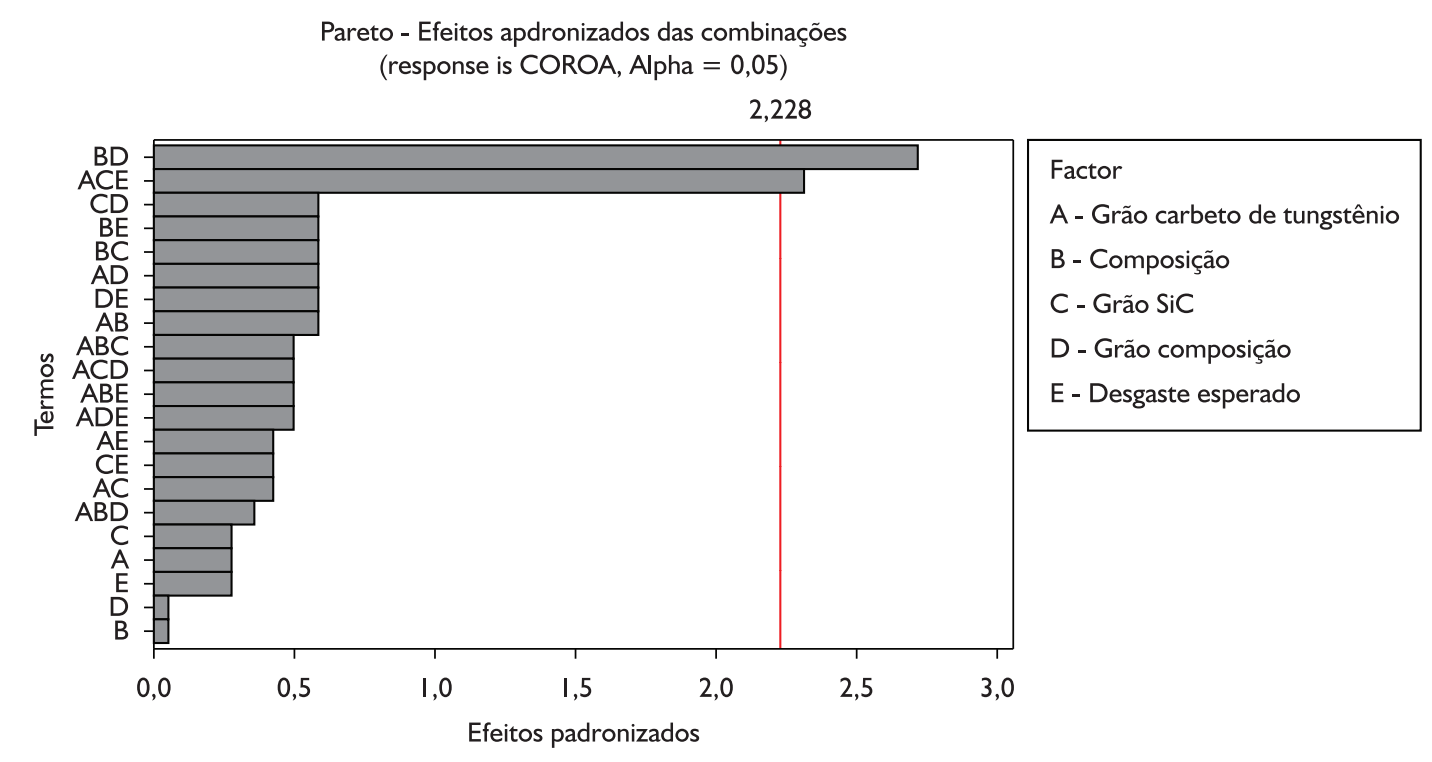

Figura 2. Pareto - efeitos padronizados. 
A Figura 2 mostra que a combinação de melhor significância está relacionada à adição do $\mathrm{Fe}, \mathrm{Cu}, \mathrm{Co}$, com granulometria entre 0,9 e 3,5, em relação à expectativa de desgaste, combinada também com carboneto de tungstênio e carboneto de silício.

A Figura 3 mostra a probabilidade normal entre os materiais e tamanhos de grãos das coroas citadas pelos técnicos no trabalho de campo. É importante ressaltar que as coroas com melhor probabilidade de otimização do desgaste são exatamente as que possuem: Fe entre I5\% (granulometria de 2,2 $\mu \mathrm{m}$ a 4,4 $\mu \mathrm{m}$ ) e $72 \%$ (granulometria 0,9 $\mu \mathrm{m}$ a $3,5 \mu \mathrm{m}$ ); Cu $3 \%$ (granulometria de 0,9 $\mu \mathrm{m}$ a 3,5 $\mu \mathrm{m}$ ), Cu $60 \%$ (granulometria de 2,2 $\mu \mathrm{m}$ a 4,4 $\mu \mathrm{m}$ ) e Co $25 \%$, carboneto de tungstênio em 99,5\%. Com base nessa informação desenvolveu-se um protótipo para validar o resultado do Planejamento de Experimentos. Utilizaram-se para o protótipo os parâmetros mostrados na Tabela 2.

Tabela 2. Composição do protótipo

\begin{tabular}{lc}
\hline \multicolumn{1}{c}{ Descrição } & Concentração (\%) \\
\hline Fe, Cu, Co $(0,9-3,5 \mu \mathrm{m})$ & 10 \\
Carboneto de silício $(38-60 \mu \mathrm{m})$ & 5 \\
Carboneto de tungstênio $(5-7 \mu \mathrm{m})$ & 85 \\
\hline
\end{tabular}

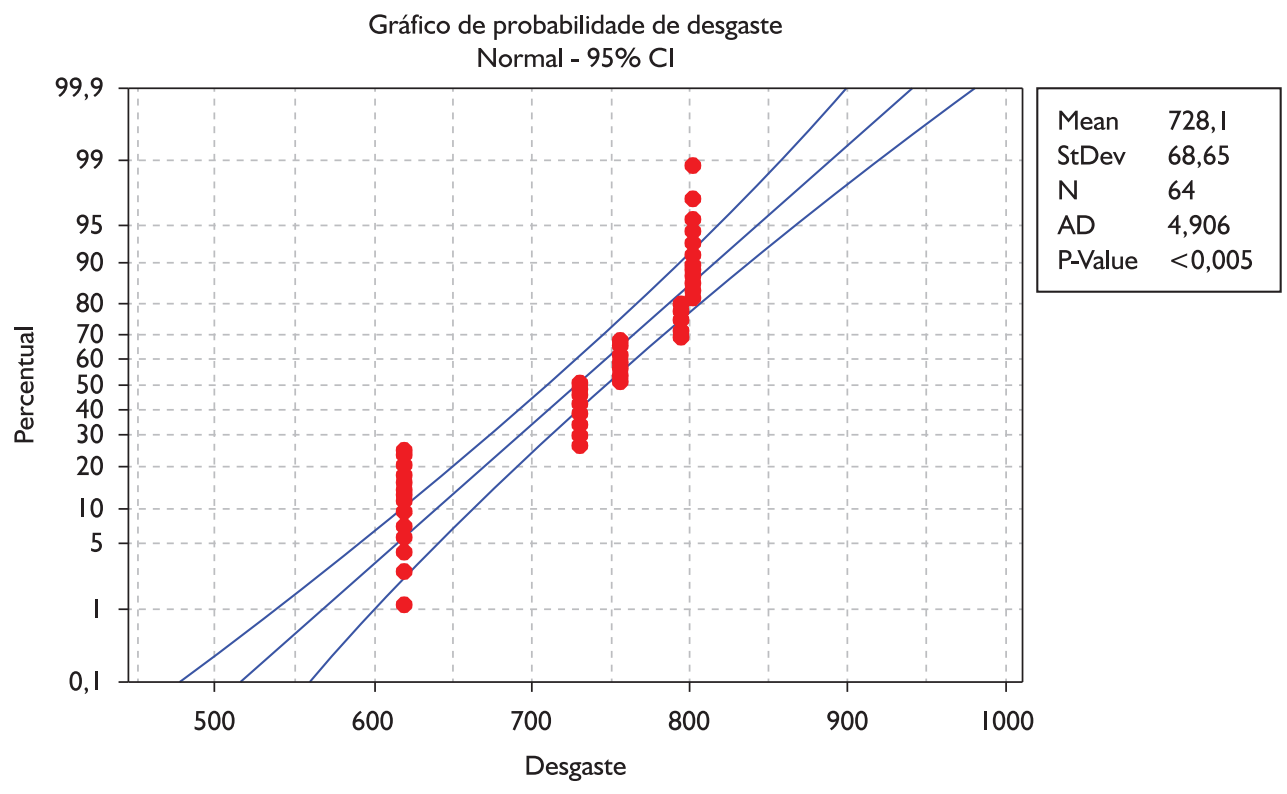

Figura 3. Probabilidade de interação entre variáveis.

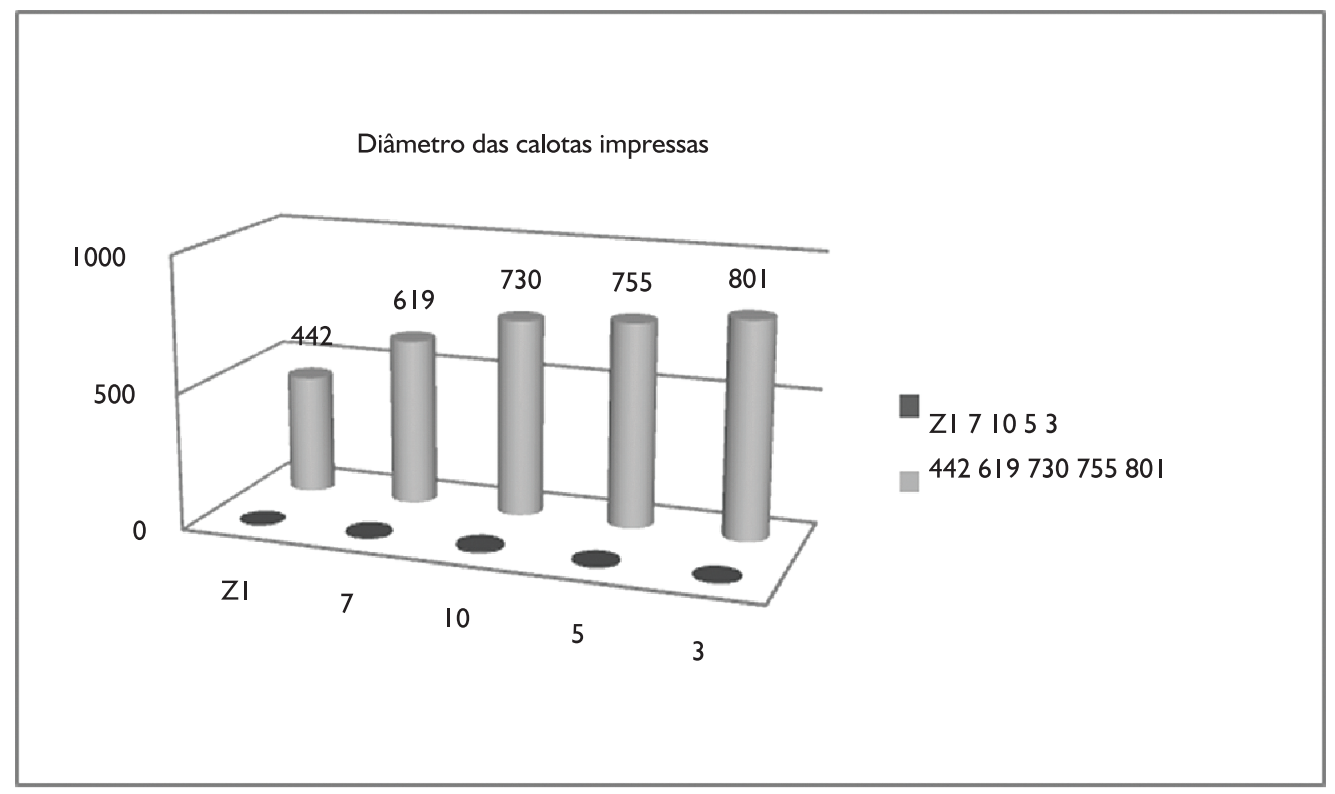

Figura 4. Diâmetro das calotas resultante dos ensaios. 


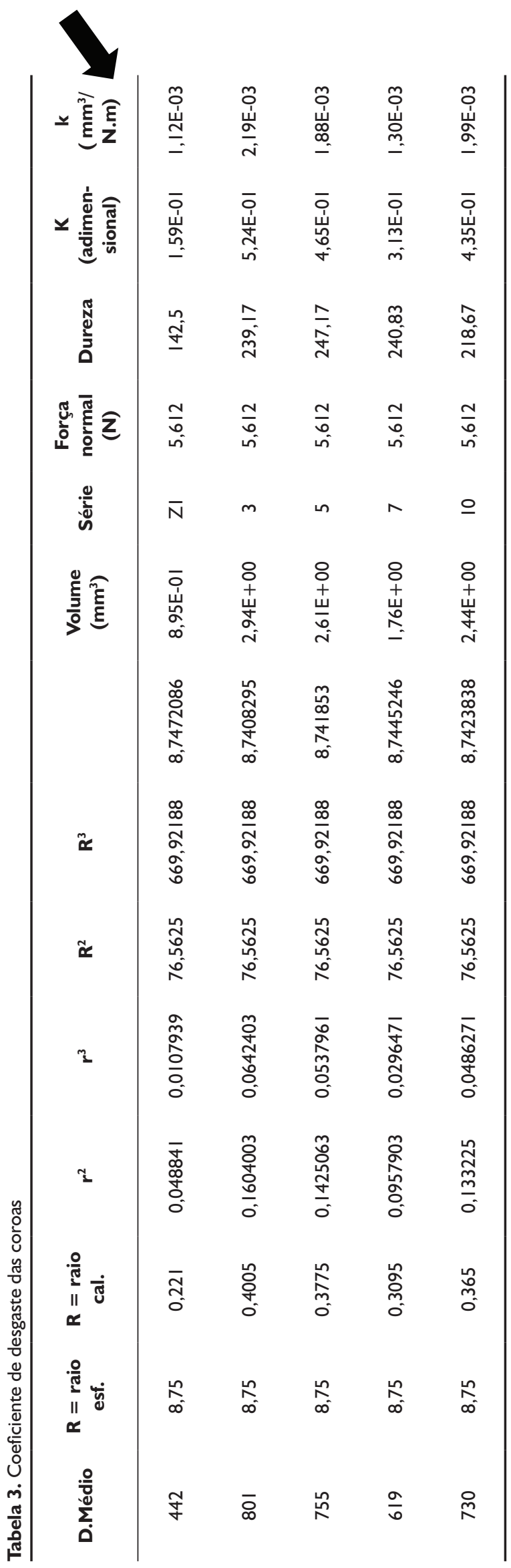

A Tabela 2 apresenta os parâmetros utilizados para desenvolvimento do protótipo, a partir do resultado advindo da aplicação do BSCEQ. Foram contemplados os elementos $\mathrm{Fe}, \mathrm{Co}, \mathrm{Cu}$, e carboneto de silício e carboneto de tungstênio. $O$ carboneto de silício foi inserido para análise no sentido de otimizar a perda de material; - carboneto de tungstênio com tamanho de grão entre $5 \mu \mathrm{m}$ e $7 \mu \mathrm{m}$ - quantidade relativa $85 \%$; o carboneto de silício com granulometria entre 38 e $60 \mu \mathrm{m}$ em $5 \%$ e a composição $\mathrm{Fe}$, Co e $\mathrm{Cu}$ com grãos entre $0,9 \mu \mathrm{m}$ e $3,5 \mu \mathrm{m}$ em $10 \%$. Após ensaio, foi constatada a perda de material, no protótipo, por meio de microscopia óptica. A Figura 3 apresenta o diâmetro da calota gerada por meio de microscopia óptica realizada no protótipo identificado como ZI. A calota impressa apresentou diâmetro de $442 \mu \mathrm{m}$. Assim, foi possível comparar o desgaste do protótipo com o desgaste das coroas citadas pelos técnicos de campo: 3, 5, 7 e 10.

$\mathrm{Na}$ Figura 4 apresenta-se a perda de material das coroas submetidas a ensaio de desgaste no laboratório definidas pelo diâmetro das calotas impressas analisadas ao microscópio óptico. Na Tabela 3 encontram-se os parâmetros utilizados para aplicação da equação de Archard (Equação I), para validar o experimento por meio do cálculo do coeficiente de desgaste.

Foi possível, portanto, comparar o coeficiente dimensional de desgaste entre $\circ$ protótipo e as coroas já utilizadas em campo e, assim, confirmar a eficiência e eficácia da metodologia para a seleção de materiais. $O$ coeficiente dimensional da calota gerada no protótipo $\mathrm{ZI}$ foi I, $12 \times 10-3 \mathrm{~mm} 3 / \mathrm{N}$.m, conforme indicado na Tabela 3.2, sendo menor que o coeficiente das calotas utilizadas em campo.

\section{CONCLUSÃO}

Este estudo evidencia que a otimização do desgaste das coroas de perfuração pode ser realizada por meio da utilização da metodologia Balanced Scorecard de Engenharia da Qualidade - BSCEQ, e contribui para apresentar uma análise estatística capaz de combinar os materiais com o resultado desejado. Assim, a redução de custo ocorre em função da redução de tempo gasto em tentativas e erros e o planejamento bem realizado gera mais segurança na seleção de materiais. No caso do processo de sondagem, ocorre aumento da vida útil das coroas e aumento da produtividade, por redução de paradas para trocas, durante o processo de sondagem.

\section{Agradecimentos}

Os autores agradecem a colaboração da empresa Geologia e Sondagem S/A- Geosol e ao Laboratório de Engenharia de Superfícies e Técnicas Afins, Escola de Minas - Universidade Federal de Ouro Preto. 


\section{REFERÊNCIAS}

I FERREIRA, C. R. Produção de coroas por indução eletromagnética. 20 I0. 154 p. Tese (Doutorado em Engenharia de Materiais) - Rede Temática de Materiais, da Universidade Federal de Ouro Preto, Ouro Preto, 2010.

2 HUTCHINGS, I. M. Tribology: criction and wear of engineering materials. Londres: Edward Arnold, 1992.

3 NUNES, R. A. X. Abrasão, desgaste e atrito sob deslizamento de recobrimentos preparados por aspersão térmica a partir de PET pós-consumo. 2008. 2 I 9 f. Tese (Doutorado em Engenharia de Materiais) - Rede Temática de Materiais, da Universidade Federal de Ouro Preto, Ouro Preto, 2008.

4 ZUM-GAHR, K. H. Microstructure and wear of materials. New York: Elsevier, 1987.

5 PINTAÚDE, G. Análise dos regimes moderado e severo de desgaste abrasivo utilizando ensaios instrumentos de dureza. 2002. 230 f. Tese (Doutorado em Engenharia Mecânica) - Escola Politécnica da Universidade de São Paulo, São Paulo, 2002. Disponível em: <http://www.teses.usp.br/teses/disponiveis/3/3 I 32/tde-070420 I0-I I I 922/> . Acesso em: II nov. $201 \mathrm{I}$.

6 CRUZ, D. C. Desgaste por abrasão de poliuretano utilizado na indústria mínero-metalúrgica; Dissertação de Mestrado, REDEMAT, Ouro Preto, Minas Gerais, 2006.

7 GATES, J. D. Two-body and three-body abrasion: a critical discussion. Wear, v. 2I4, n. I, p. I39-46, Jan. 1998. http://dx.doi.org/I0.1016/S0043-1648(97)00188-9

8 KAPLAN, R. S.; NORTON, D. P. A estratégia em ação: balanced scorecard. Rio de Janeiro: Campus, 1997.

9 JURAN, J. M. A qualidade desde o projeto: novos passos para o planejamento da qualidade em produtos e serviços. São Paulo:Thomson, 1992.

IO MONTGMOMERY, D. C. Introdução ao controle estatístico da qualidade. 4. ed. Rio de Janeiro: LTC, 2004.

Recebido em: $25 / 01 / 2012$

Aceito em: 25/05/2012 